\title{
TEACHING AND LEARNING
}

\section{Planning First-Year Hybrid Instruction at Scale Before, During, and After the Pandemic: A Case Study}

\author{
ABIGAIL E. MORGAN \\ ORCID ID https://orcid.org/0000-0003-2351-4517 \\ Miami University, Oxford, $\mathrm{OH}$ \\ morgan55@miamioh.edu
}

\begin{abstract}
Column introduction A number of factors impact the development and delivery of business information literacy instruction, such as professional frameworks, business school curricula, and research assignment outcomes. Abigail Morgan's article discusses a number of these factors while describing how two business librarians worked with the Farmer School of Business at Miami University to create, implement, and assess a hybrid, one-shot lesson plan for first-year business students. There was a need for the lesson plan to be scalable and adaptable during the pandemic. Readers will have access to the assignments used and to details about how the instructional content was scaffolded across a course of 1,000 students. The instruction changed with each iteration that was taught and as new parameters were introduced to the process. Lessons that were learned along the way are also included. - Sandy Miller and Christina Sheley, column editors
\end{abstract}

\section{Background}

Miami University is a state school located in rural Ohio with approximately 17,000 undergraduate students and a very strong institutional focus on teaching (Miami University, n.d.). In 2020, the Farmer School of Business (FSB) at Miami University enrolled 4,375 undergraduate students (Office of Institutional Research and Effectiveness, n.d.). There is one Business Librarian, who is the liaison to all of the business school, and one Social Sciences Librarian, who serves the Marketing department, the First-Year Integrated Core (FYIC) program, and the Economics department, which is located in FSB. (These two librarians will be collectively referred to as the business librarians for the rest of this article.)

The FYIC program began in the 2016-2017 academic year and includes a robust series of four courses that are required for all undergraduate students who enter as declared business majors. Students are registered to take all four classes simultaneously in either the fall or spring semester. These courses are Foundations of Business; Foundations of Business Communication; Creativity, Innovation and Entrepreneurship; and Introduction to Computational Thinking for Business. Every year, students are given a client challenge conducted across the FYIC classes that culminates in a group project where students present their research findings. The client is typically a large regional corporation such as Fifth Third Bank or the Cleveland Clinic.

In addition to the foundational core classes, all first-year business students must take a one-credit college transition course called Farmer School of Business Success Strategies (BUS 106) in the fall semester. This course "will provide business students with the resources, tools, and information to support personal, academic, and career goals," (Miami University, 2021).

Although BUS 106 can be taken concurrently with FYIC, it is administered through the advising office, and the programs have two different directors. In 2020, there were 34 sections of BUS 106 . Since there are so many 
sections, it is not feasible for the two business librarians to speak to each one. In addition, there is a considerable amount of content that is mandated in BUS 106 regarding university policies, and it is taught as a compressed six-week sprint course. The advising office's solution was to combine 4-5 sections (totaling 150-370 students) into larger, 65-minute classes on certain Fridays throughout the fall semester. This meant that on one Friday, business librarians could see all 800-1,000 first-year business students for approximately twenty minutes of in-class time. Novel solutions had to be pursued in order to scale instruction and properly scaffold the content in BUS 106 so it could be applied later in the FYIC classes.

\section{Pre-pandemic Development}

The business librarians jumped at the opportunity to reach all first-year business students, since they had never been able to speak to or schedule individual research consultations with all of them. While a number of students sought librarian assistance on their own, or if directed by their instructor, it felt unfair that some students received more help than others. Creating a lesson on library resources for BUS 106 was a satisfying development.

In July 2018, librarians first collaborated with both the Assistant Dean \& Director of Divisional Advising and the Director and Assistant Director of the FYIC program. At these initial meetings, both expressed an interest in impressing on students the importance of using library resources to find strong and credible research and proper citation. In the past, librarians had created a course guide tailored to the client challenge that provided many industry reports for students. However, the directors wanted to move away from giving students too many resources upfront, so they had to do more aggressive independent research themselves. The suggestion of a flipped classroom approach to the library session instead of a course guide was first raised in these initial meetings.

After meeting with BUS 106 and FYIC coordinators, the business librarians drafted an assignment that asked students to create a reference list on business ethics that included five sources from multiple databases, all cited properly in APA format. Ultimately it was decided that the assignment would be too time consuming to grade. With that parameter in mind, the business librarians reexamined the key takeaways from that draft, which informed the learning objectives in the final lesson plan, being mindful that there would be future opportunities to meet with students again when their information needs had evolved.

\section{Lesson Outline}

The business librarians ended up developing a lesson that contained two discrete parts--an online flippedclassroom component (Part 1) that provided foundational information and an in-class practice exercise (Part 2), which allows students to apply that knowledge. Final assignment examples from 2020 are in in the Appendix.

The three main learning outcomes for the lesson are:

1. Understand how to navigate the library website and who to contact with questions,

2. Know how to find and identify business databases,

3. Understand that business research is complex and requires using multiple sources of information to answer questions.

The two parts of the lesson and the learning outcomes are designed to move through the bottom three layers of Bloom's Taxonomy of remember, understand, and apply (Armstrong, 2010). This scaffolds the 
Ticker: The Academic Business Librarianship Review, 6:1 (2021)

https://doi.org/10.3998/ticker.1378

(C)2021 Abigail E. Morgan

instruction appropriately for the first instance of library instruction for business students in the very beginning of their college careers.

During the flipped classroom portion, students were required to watch video tutorials on three business databases that librarians selected for their relevance to the client challenge project. The first video covers the MarketLine database and introduces students to company research. The second video describes Statista and details how it can be used to quickly find data. The third video is on Business Source Complete and discusses how to find research articles. The videos were created internally with the assistance of the Instructional Design Librarian.

After each video, students were asked three or four questions about the database. These questions were designed to be simple fact-check questions on the purpose for each database and what could be found therein. This section was designed to be simple since it was entirely online. More complicated questions could be asked when librarians would be available in class.

For the in-class portion, slides were created to introduce students to the library's location and hours, as well as the chat services available. During class, the business librarians would introduce themselves to the students and explain how to select a large public company in order to address the first question of the Part 2 exercise. Then students were asked to complete a search exercise using MarketLine and Statista to find information on that company. Students then built a basic search in Business Source Complete on a broad business issue and narrowed that search. When applicable, students were asked to find citations in databases, if available. While students worked independently, librarians would walk around and assist as needed. This provided another opportunity to demonstrate research services to students.

Since 2018, Part 2 of the lesson has been updated to reflect changes in the overall focus of the combined course session. In 2019, the focus switched from academic integrity to academic support. To reflect this, business librarians changed the issue in Part 2 from business ethics to productivity. In 2020, the focus remained on academic support, but based on observations from the in-class exercise, Part 2 was rewritten to be less confusing to students, and the business issue was updated to remote work.

\section{Pandemic Adjustments: Changing Modes}

In order to comply with the social distancing requirements of the pandemic, BUS 106 was switched to an entirely online class in fall 2020. Part 2 of our lesson was also moved online, thereby creating a completely asynchronous lesson. Both parts already resided in the course management system, and the learning outcomes also remained the same. However, the change in format overall felt emptier from an instruction standpoint compared to the hybrid version since it was so removed from the students.

For Part 2, an introductory video focused on the library and library services was created in an attempt to simulate some of the in-class engagement. In the video, one of the business librarians explained how to contact the library with questions, why certain databases were selected for the assignment, as well as how the knowledge gained from completing the module would be applicable in later classes. This was the first time the business librarians had attempted a classroom video without the help of the Instructional Design Librarian and was the first BUS 106 video not designed as a database tutorial, which meant they had to grapple with acquiring new skills. Due to inexperience, there are many novice mistakes in the video itself, such as poor eye contact with the camera, low sound quality, and using only one take with no edits from beginning to end. The video itself has only been viewed 109 times to date, which is a remarkably low engagement rate. Ultimately, the video was not considered to be an adequate replacement for meeting with students in person. 
Ticker: The Academic Business Librarianship Review, 6:1 (2021)

https://doi.org/10.3998/ticker.1378

(C)2021 Abigail E. Morgan

In fall 2021, classes are expected to return to face-to-face instruction. It is still unknown if BUS 106 will be among those classes; however, even if the smaller sections are held face to face, it is possible that the large combined Friday classes will need to be held online. Therefore, business librarians are preparing the lesson for either format.

If BUS 106 stays fully online, the simplest solution will be to revise the asynchronous module from 2020. However, because the introductory video had so little impact, the business librarians question whether it merits spending time to remake. If the large combined Friday classes do go forward, it should be a fairly seamless transition back to the flipped component followed by normal classroom instruction.

\section{Assessment}

To assess student learning, BUS 106 students complete two graded assignments--a short quiz in Part 1 and a practice activity in Part 2. To evaluate the perceived usefulness of the lesson, in either its hybrid form or the completely online module, students were also asked to complete an optional exit slip. While the exit slip is housed on Springhare's LibWizard and can be viewed by the librarians any time, FSB maintained the grading records on the quiz and the Part 2 exercise for each section of BUS 106. In order to receive a compiled average grade report, it was necessary to rely on strong connections with the FSB coordinators. Being able to share assessment outcomes equally and across campus units has been invaluable in making the instruction better each year.

In 2018, 811 students completed the quiz, with an average grade of 9.13/10 (91\%), and 797 completed Part 2, with an average grade of 9.8/10 (98\%). This indicates that students understood the material and were able to successfully use that knowledge to search library databases. It also shows that the lesson achieved its main objective of introducing three foundational business databases to all first-year business students. Of the 718 students who completed the exit slip, 93\% responded that the lesson was useful (Table 1).

In 2019, librarians did not obtain a compiled report of the grades from FSB. Feedback from the exit slip indicated that $96 \%$ of students found the lesson useful, and librarians were pleased to see an increase in satisfaction in the second year.

\begin{tabular}{cccc} 
Year & Useful & Not Useful & Response Rate/Total Responses \\
\hline 2018 & $93 \%$ & $7 \%$ & $85 \% / 718$ \\
2019 & $96 \%$ & $4 \%$ & $80 \% / 913$ \\
2020 & $97 \%$ & $3 \%$ & $85 \% / 898$
\end{tabular}

Table 1. Student Evaluation of Usefulness of the Library Resources Module.

In 2020, a total of 1,057 students completed the quiz, with an average grade of $9.04 / 10(90 \%)$, and 1,057 completed the activity with an average grade of $19.4 / 20$ (97\%). Of the 898 students who completed the exit slip, $97 \%$ indicated the module was useful (Table 1). Librarians were surprised that the entirely online module had even higher positive feedback than the previous years. They anticipated that students would have more negative feedback because they would not find the module as compelling. Librarians were also somewhat surprised to receive such a high response rate to the exit slip, which they anticipated would decrease based on 
metrics from other online learning objects. Perhaps because the exit slip is incorporated into a graded assignment, students felt like they must answer it to complete the exercise.

Most of the critical student feedback from the exit slip in all three years mentioned that the exercise felt repetitive or like busy work. The graded quiz and exercise are not designed to be difficult, but since both received very high average grades, that could signify some students are not being challenged enough.

\section{Future Directions}

For 2021, business librarians want to revise both parts of the lesson to include more critical thinking in order to deepen the learning experience and address the busy-work concerns.

The foremost modification to the lesson planned for 2021 is to incorporate critical thinking concepts from the Business Research Competencies (BRC) published by the Reference and User Services Association (2019). The two Foundational Competencies on the Business Information Environment and Business Research Strategies and Techniques are especially relevant to the class and align well with the learning outcomes. These two competencies describe the basic understandings about business information that students should find helpful when conducting their own research in FYIC. 2021 will be the first instance that librarians will have the chance to include the BRC since it was not published until late 2019, and significantly updating the lesson in 2020 seemed unwise while also moving fully online.

Business librarians will look to replace a number of the questions in the Part 1 quiz and Part 2 exercise with more thought-provoking questions on the credibility of sources and comparing the information found in each database. This should make both these components more interesting, while maintaining the introductory nature of the lesson.

\section{Lessons Learned}

Keeping the scale of the lesson in mind is crucial. Since BUS 106 is such a rare opportunity with a captive audience, there is constant temptation to add more databases and concepts. However, there is a danger of introducing too much complexity to the lesson, perhaps inadvertently leading to poorer student outcomes. Trusting in the positive assessment results should prevent business librarians from over-encumbering the lesson and serve as a reminder to set realistic expectations for the class.

Throughout the development of the lesson for BUS 106, collaboration with FSB and other librarians has been vital. Listening to stakeholder needs has set the foundation for a strong, lasting partnership between the business school and the library, even during the upheaval of the pandemic. Open communication will remain a key factor when updating the module in 2021 so that it can be even better for first-year students.

While the planning and execution of the information literacy instruction session for BUS 106 is under the domain of the business librarians, other librarians are routinely enlisted to assist since working with such a large number of students limits the amount of individual assistance business librarians can provide. Furthermore, students often use the library's chat reference service to ask for help with Part 1 and Part 2 of the lesson, so the business librarians are always mindful to apprise colleagues about the assignment, the date, and how to answer the questions to the quiz and the Part 2 activity. This support is essential in the sustained success of the BUS 106 lesson because it ensures that all students receive the help they need. 
Ticker: The Academic Business Librarianship Review, 6:1 (2021)

https://doi.org/10.3998/ticker.1378

(C)2021 Abigail E. Morgan

In 2021, FSB is welcoming its largest ever first-year class. It is fortunate that the library and FSB have already created a library lesson with the ability to scale up. Although the exact format of BUS 106 is still in question, it is reassuring to have a lesson prepared that has been successful in both hybrid and online formats. 
Ticker: The Academic Business Librarianship Review, 6:1 (2021)

https://doi.org/10.3998/ticker.1378

(C)2021 Abigail E. Morgan

\section{References}

Armstrong, P. (2010). Bloom's Taxonomy. Vanderbilt University Center for Teaching. https://cft.vanderbilt.edu/guides-subpages/blooms-taxonomy/

Miami University. (2021). General Bulletin 2021-2022 - Business Analysis (BUS). Retrieved June 1, 2021, from https://bulletin.miamioh.edu/courses-instruction/bus/

Miami University. (n.d.). Miami at a glance. Retrieved June 1, 2021, from https://miamioh.edu/about-miami/quickfacts/index.html

Office of Institutional Research and Effectiveness. (n.d.). Miami University enrollment - 15th day of classes. 5-Year history: Fall 2016 to Fall 2020 by campus and college/school. Miami University.

https://www.miamioh.edu/oir/_files/documents/fbook/20-21/enrollments/15th-day/5yr-campus-college-fall.pdf

Reference and User Services Association. (2019). Business Research Competencies.

http://www.ala.org/rusa/guidelines/business-research-competencies 
Ticker: The Academic Business Librarianship Review, 6:1 (2021)

https://doi.org/10.3998/ticker.1378

(C)2021 Abigail E. Morgan

Appendix

Lesson Materials

\section{Part 1}

\section{BUS 106 Library Resources Part 12020}

Students should watch three videos on Library databases and answer the following questions before class. Bold indicates the correct answer.

Video One: MarketLine (https://youtu.be/bUcLru4BLQU)

Question 1:

What kind of information can you find in a company report in MarketLine?

a. Detailed consumer information and statistics

b. Financial information and main competitors

c. Up to the minute stock prices

d. Company training manuals

Question 2:

You can find industry reports for other countries in MarketLine.

a. True

b. False

Question 3:

What kind of information can you find in a country report in MarketLine?

a. A detailed census of their population

b. A map of the country with all the major business headquarters on it

c. How to say business related words in their language

d. What it is like to do business in that country

Video Two: Statista (https://youtu.be/JsxLzZXIe0g)

1) Statista only has data from the United States? True/False

2) If you find a chart on Statista you can...

a. Cite the chart

b. Modify the way the chart looks

c. Download the chart

d. All of the above

3) A dossier of a company from Statista consists of...

a. A detailed written report on the company

b. A forecast of the company's stock price

c. A comic about how the company was founded

d. A collection of charts about the company 
Ticker: The Academic Business Librarianship Review, 6:1 (2021)

Video Three: Business Source Complete (https://youtu.be/x0NQsiRlj90)

1) How do you access Business Source Complete
a) Library website
b) ebsco.com
c) Ebscohost
d) Google

2) You would use Business Source Complete to find...
a) books
b) journal articles
c) kitten videos
d) government statistics

3) If the full text of an article is not in Business Source Complete, you could...
a) Try finding it through the Find It Button
b) Order it for free through interlibrary
c) Contact a librarian to help you look for it
d) All of the above

\section{Part 2}

\section{BUS 106 Library Resources Part 2 (2020)}

\section{$1-\mathrm{A}$}

Choose a company to research for this exercise. TIP: choose a large, popular company for this - maybe a company where you recently purchased something for starting college. Some ideas: Apple, HP, Dell, Target, Starbucks, Bed Bath and Beyond, Amazon, etc.

What is your company?

\section{2-A}

Go to the MarketLine database. This is linked on the BUS 106 Library Page https://libguides.lib.miamioh.edu/BUS106

Put your company name in the Keyword box at the top of the screen and change the dropdown box on the right from "All Research" to "Company Profiles" from the dropdown box.

From your result list, make sure you find "Parent" next to the company name. Then answer the following questions:

I. Where is the company headquarters?

II. How many employees do they have?

III. What is their annual revenue? 
Ticker: The Academic Business Librarianship Review, 6:1 (2021)

https://doi.org/10.3998/ticker.1378

(C)2021 Abigail E. Morgan

\section{2-B}

Click on the name of the company to open the report online. Click on "Profile" on the left, then scroll down to "Products and Services."

I. Copy and paste the sentence that describes the company's main business:

II. List the first three products they produce:

2-C

Click on the "Peers" tab on the left.

Who is the top competitor for this company?

3-A

Go to the Statista database. Search for your company using the search box, then select the statistic that looks most interesting to you. (TIP: make sure you are clicking on a statistic with a blue chart icon). If you can't find a relevant statistic, try different keywords or ask a librarian for suggestions to improve your search.

What is the title of the statistic?

3-B

Once you are on the screen for the statistic, look for the Citation button - the quote symbol on the right side of the chart. Choose APA and copy and paste the citation here.

3-C

What is the source of the data? (This is in the box on the right hand column).

3-D

Next, scroll all the way down to the bottom of the page to Further Content. What are the first three related Topics listed on the right hand side?

4-A

Go to the Business Source Complete database. Do a search for articles about remote work. How many articles did you find?

4-B

Now further limit your search to Scholarly Articles that are just from 2010 to present, (hint, these limiters are both on the left side of the screen). Now how many articles do you have?

4-C

Now add in another term to narrow the search in the 2nd search box. Type in the company you are researching.

How many articles do you have now? (This number may be quite low or zero) 
Ticker: The Academic Business Librarianship Review, 6:1 (2021)

https://doi.org/10.3998/ticker.1378

(C)2021 Abigail E. Morgan

4-D

Unclick the Scholarly Articles limiter - how many articles do you have now?

4-E

Now click on the Share button on the top right side over your list of search results and copy the Permalink for your search. This saves this search for later without having to re-do the previous steps. Copy and paste the link here.

4-F

Return to your list of articles and find one that has PDF or HTML full-text available. Click on the title of the article to open up the record. What is the title of the article? What magazine or journal is it in and what is the date? (Hint - this should be around the middle or bottom of the screen in the SOURCE field.)

4-G

Find the Cite tool on the right side - copy and paste the citation for APA style.

4-H

Now click on Result List to go back to the list of results and see if there are ANY articles in your first page of results that have a yellow "Find It" button. This button means it might be available from another database. If ALL the articles on your $1^{\text {st }}$ page of results have HTML or PDF full-text links, click N/A.

When you click on the Find It button, do we have full-text access to it online -

Yes $\square$ or No $\square$ N/A

5-A

Go to the BUS 106 Library page (https://libguides.lib.miamioh.edu/BUS106) and click on the link for the Wall Street Journal and create a new account. Once you have an account set up - sign in and write down a headline from the front page. (If you already have a WSJ account - just sign in and find a headline.)

6-A

Last but NOT Least - PLEASE take this 1-minute survey to help us improve this module.

https://muohio.libwizard.com/f/BUS106-2020 - THANKS!!! 